\title{
A família Aristolochiaceae Juss. no estado do Paraná, Brasil ${ }^{1}$
}

\author{
Dilma Silva do Nascimento ${ }^{1,3}$, Armando Carlos Cervi² e Olavo Araújo Guimarães ${ }^{2}$
}

Recebido em 8/01/2009. Aceito em 4/03/2010

RESUMO - (A família Aristolochiaceae Juss. no estado do Paraná, Brasil). O presente trabalho trata do estudo taxonômico das espécies de Aristolochiaceae ocorrentes no Estado do Paraná. Por meio de estudos de levantamento em herbários, coletas e observações, foram constatados dez táxons pertencentes ao gênero Aristolochia L.: A. chamissonis (Klotzsch) Duch., A. elegans Mast., A. fimbriata Cham. \& Schltdl., A. gigantea Mart. \& Zucc., A. melastoma Silva Manso ex Duch., A. odoratissima L., A. paulistana Hoehne, A. triangularis Cham., A. trilobata L. e A. wendeliana Hoehne. A. fimbriata é citada pela primeira vez para o Estado do Paraná. Chaves de identificação, descrições e ilustrações são também incluídas neste trabalho.

Palavra-chave: Aristolochia, Aristolochiaceae, Paraná, taxonomia

ABSTRACT - (The family Aristolochiaceae Juss. in Paraná state, Brazil). A taxonomic treatment of the species of Aristolochiaceae from Paraná state is presented. The floristic survey revealed ten taxa of the genus Aristolochia L.: A. chamissonis (Klotzsch) Duch., A. elegans Mast., A. fimbriata Cham. \& Schltdl., A. gigantea Mart. \& Zucc., A. melastoma Silva Manso ex Duch., A. odoratissima L., A. paulistana Hoehne, A. triangularis Cham., A. trilobata L. and $A$. wendeliana Hoehne. The first report of $A$. fimbriata is presented for Paraná state. An identification key, descriptions and illustrations of the Aristolochia species are also given.

Key words: Aristolochia, Aristolochiaceae, Paraná state, taxonomy

\section{Introdução}

A família Aristolochiaceae é constituída por quatro gêneros e aproximadamente 600 espécies presentes em regiões tropicais, subtropicais e temperadas de todo o mundo (González 1990; Capellari Jr. 2001). É conhecida vulgarmente como a família da jarrinha, papo-de-peru, caçaú e cipó mil-homens (Capellari Jr. 2002). Suas espécies são empregadas com fins farmacológicos por populações indígenas e rurais (Schvartzman 1975). Aristolochia L. é o gênero que reúne o maior número de espécies da família e abrange parte da vegetação tropical e subtropical, apresentando maior densidade na faixa tropical (González 1990). No estado do Paraná a família abrange espécies distribuídas nas diversas formações vegetacionais. Segundo Roderjan et al. (2002), o estado paranaense possui cinco grandes unidades fitogeográficas: Floresta Ombrófila Densa (Floresta Atlântica), situada na porção leste do estado e definida praticamente em toda sua extensão pela Serra do Mar, com altitude máxima de 1.887 m; Floresta Ombrófila Mista (Floresta com Araucária), situada na porção oeste da serra, ocupando as porções planálticas do estado, com altitude entre 800 e 1.200 m; Floresta Estacional Semidecidual (Floresta Estacional), situada nas regiões norte e oeste do estado e nos vales dos rios formadores da bacia do rio Paraná, com menos de $800 \mathrm{~m}$. de altitude; Estepe Gramíneo-lenhosa (Campos Limpos), entremeados por capões e florestas de galerias, localizados nas porções mais elevadas dos planaltos paranaenses; Savana Arborizada (campos cerrados), localizada nas regiões norte e nordeste do estado.

Geralmente são providas de rizomas ou tubérculos (Hoehne 1942). Ocorrem em diversos tipos de vegetação, predominando em áreas abertas como regiões de Savana (Cerrado) e Floresta Decidual, geralmente em orla de florestas e rios. Incluem lianas e herbáceas. Pseudoestípulas, ocorrem na maioria das espécies, principalmente nas lianas. Segundo diversos autores (Ahumada 1967; Pfeifer 1966; Hoehne 1942; González 1990), as pseudoestípulas são profilos de ramos axilares atrofiados, ou seja, segundo Duchartre (1864), não mais que as primeiras folhas não desenvolvidas.

Uma primeira divisão na família, proposta pelos autores Duchartre (1864), Engler (1912), Hoehne (1927), Gregory (1956), González (1990), consideravam seis gêneros. Atualmente, quatro gêneros são reconhecidos dentro de Aristolochiaceae: a subfamília Asaroideae com os gêneros Saruma Chodat \& Hassler, monotípico e endêmico da China Central e Asarum L. com 86 espécies distribuídas em áreas temperadas da América do Norte, Europa e Ásia; a subfamília Aristolochioideae, com os gêneros Thottea Rottboele, com aproximadamente 30 espécies restritas à Ásia tropical e o gênero Aristolochia L., com aproximadamente 400 espécies distribuídas em quase todas as regiões tropicais e subtropicais do globo (Wanke et al. 2007);

A família apresenta uma distribuição por todo o Brasil, sendo representada no país somente por Aristolochia (Ahumada 1967; González 1997; Kelly 1998; Wanke et al. 2007). Alguns estudos foram realizados para o Brasil: Masters (1875) reconheceu cerca de 48 espécies do gênero Aristolochia, e estabeleceu três seções para a família; Hoehne (1942) reconheceu cerca de 90 espécies para o país; Capellari Jr. (1991) constatou 16 espécies para o estado de São Paulo; Pereira (1959) reconheceu oito espécies da família para a cidade do Rio de Janeiro; Ahumada (1975) realizou um levantamento em Santa Catarina, na qual constatou 14 espécies de Aristolochia; Ahumada (1977, 1979) descreveu duas novas espécies para o Brasil; Bazzolo \& Pfeifer (1977) citaram quatro espécies para o Brasil, Colômbia e Venezuela; Barros (1981) descreveu duas espécies para a Flora da Reserva do Parque Estadual das Fontes do Ipiranga (SP); Mendonça et al. (1998) constataram duas espécies para a

\footnotetext{
Parte da dissertação de Mestrado da primeira Autora

Universidade Federal do Paraná, Departamento de Botânica, Curitiba, PR, Brasil

Autor para correspondência: dilmika@hotmail.com
} 
Flora Vascular do Cerrado; Capellari Jr. (2001) constatou oito espécies para a Flora dos Estados de Goiás e Tocantins; Cavalcanti \& Ramos (2001) levantaram três espécies para a Flora do Distrito Federal; González (2002) citou uma nova espécie de Aristolochia para a Bahia; Batalha \& Jorge (2003) citaram a ocorrência de apenas uma espécie de Aristolochia para a Flora de Grão-Mogol (MG); Schinini \& López (1997) citaram a espécie A. melastoma para o Parque Nacional Iguaçu (PR); Barros \& Capellari Jr. (2004) levantaram três espécies para a Flora da Serra do Cipó (MG).

$\mathrm{O}$ presente estudo tem como objetivo contribuir para o conhecimento de Aristolochiaceae para a flora do Estado do Paraná, através chaves de identificação, descrições, ilustrações e comentários sobre aspectos morfológicos e ecológicos.

\section{Material e métodos}

Área de estudo - O estado do Paraná localiza-se na região Sul do Brasil, abrangendo $199.554 \mathrm{~km}^{2}$. Limita-se ao norte com o estado de São Paulo, ao sul com o estado de Santa Catarina, a leste com o Oceano Atlântico, a noroeste com o estado de Mato Grosso do Sul, a oeste com o Paraguai e a sudoeste com a Argentina (Maack 1981).

Trabalho de campo e material herborizado - Foram realizadas expedições de coleta em diferentes estações do ano para a obtenção de dados das espécies em campo, como o ciclo biológico, características morfológicas, floração, frutificação e ecologia. O material coletado foi processado de acordo com as técnicas usuais, descritas por Radford et al. (1974), e em alguns exemplares as flores foram conservadas em álcool $70 \%$ para as ilustrações. As exsicatas foram incorporadas no herbário do Departamento de Botânica da Universidade Federal do Paraná (UPCB) e Museu Botânico Municipal de Curitiba (MBM).

Foram examinados materiais presentes nas coleções dos seguintes herbários: FUEL, HBR, HFIE, HUCP, MBM, PACA e UPCB. As siglas seguem o Index Herbariorum (Holmgren et al. 1990).

Tratamento - Para as descrições foram utilizadas terminologias baseadas em Ferri et al. (1981), Lawrence (1977) e Stearn (1983). Para identificação, sinonímias e etimologia, foram utilizadas as obras de Hoehne (1942), Pfeifer (1960; 1966), Ahumada $(1975 ; 1967)$ e González (1990).
Para a mensuração de estruturas (comprimento e largura), foram utilizados régua milimetrada e paquímetro (folhas, pecíolos, frutos, flor) e para estruturas menores, tira de papel milimetrado com escala de $0,5 \mathrm{~mm}$ (ginostêmio). As abreviações utilizadas são alt. (altura), aprox. (aproximadamente), compr. (comprimento), larg. (largura), diâm. (diâmetro) e n.v. (não visto). Em relação ao material examinado, foram utilizadas as abreviações "s.d." e "s.n." para os casos em que não consta a data de coleta ou o número de coletor, respectivamente. Para designação de flor e fruto, são usadas as siglas "fl." e "fr.", respectivamente.

Em material herborizado, para análise e ilustração da estrutura floral (ginostêmio), foi seguido o tratamento de reidratação da unidade floral, através do aquecimento em água e análise com o auxilio de microscópio estereoscópico binocular.

As ilustrações foram feitas pela autora, em grafite e posteriormente cobertas a nanquin sobre papel vegetal.

\section{Resultados e discussão}

Aristolochia L.

Espécie-tipo: Aristolochia rotunda L. Sp. P1. 2: 960. 1753.

Lianas volúveis ou decumbentes, ou ervas eretas ou prostradas, tuberosas. Ramos sulcados-estriados. Pseudoestípulas ausentes ou presentes, neste caso, amplexicaules. Folhas alternas, simples, inteiras, lobadas ou tripartidas; pecioladas ou subsésseis. Flores axilares, solitárias, às vezes em racemos, monoclamídeas. Perigônio gamopétalo, zigomorfo, dividido em utrículo, tubo floral e lábio ou lábios; lábio unilabiado ou bilabiado, peltado ou prolongado em apêndice; tubo infundibuliforme, curvado ou ascendente, alargando-se para os lábios; utrículo inflado, oval a elipsóide; anteras 5-6, tetraloculares, de deiscência longitudinal, adnatas ao ginostêmio; ginostêmio pedicelado a séssil, estipitado, oval ou campanulado, com 3,5 ou 6 lobos estigmáticos. Ovário ínfero, 5-6-carpelar. Frutos capsulares, septígrafos; sementes triangulares a ovaladas, achatadas, com rafe ou aladas.

Chave para as espécies de Aristolochia L. no estado do Paraná, Brasil

1. Plantas com pseudoestípulas

2. Flor unilabiada

3. Folha com lâmina deltóide-triangular, triangular-lanceolada a deltóide-lanceolada ou hastiforme

4. Flor com lábio peltilabiado, subiorbicular, $0,9-2 \mathrm{~cm} \times 0,7-2 \mathrm{~cm}$............................................ A. triangularis

4. Flor com lábio peltado, oblongo a ovalado, 3,9-9 x 3,2-5,6 cm............................................ 6. A. odoratissima

3. Folha com lâmina cordiforme a cordiforme-ovalada ou deltóide-cordiforme

5. Flor com lábio peltado, subovalado $27-37$ x 20-27 cm .

4. A. gigantea

5. Flor com lábio peltado, ovalado, 5,2-8,3 x 3-6,6 cm. 2. A. elegans

2. Flor bilabiada

6. Lâmina foliar deltoide-triangular 7. A. paulistana

6. Lâmina foliar trilobada. 9. A. trilobata

1. Plantas sem pseudoestípulas

7. Ervas

3. A. fimbriata

7. Lianas

8. Lâmina foliar 3-5-lobada 10. A. wendeliana

8. Lâmina foliar inteira

9. Flor com lábio bilabiado, superior oval-lanceolado, 2-2,9 cm, ápice acuminado; inferior muito reduzido; Lâmina foliar oval-lanceolada, $11,4-23 \times 4,3-15,4 \mathrm{~cm}$ 1. A. chamissonis 9. Flor com lábio subpeltado, ovalado e côncavo, 1,5-3 x 1,2 cm, margem verrugosa, ápice acuminado; Lâmina foliar lanceolada a oval-elíptica, 5,6-15,4x1,4-2,9 cm. 5. A. melastoma 
1. Aristolochia chamissonis (Klotzsch) Duch., Prodr. 15(1): 462. 1864.

Fig. 1

Liana. Ramos cilíndricos, sulcado-estriados, com tricomas isolados, entrenós 6,3-19,8 cm compr. Pseudoestípulas ausentes. Folhas com pecíolo de 3,4-12 cm compr., com tricomas isolados; lâmina oval-lanceolada, raro cordiforme, 11,4-23 x 4,3-15,4 cm; face adaxial glabra, face abaxial pubescente principalmente nas nervuras; base arredondada ou levemente cordada; ápice agudo, às vezes obtuso; 3-5-venada. Flor solitária, axilar; pedúnculo 5-8,5 cm compr., pubescente; perigônio bilabiado, levemente pubescente; externamente amarelado com estrias vinosas; lábio superior oval-lanceolado, 2-2,9 cm compr., metade superior acuminada levemente retorcida; lábio inferior reduzido. Tubo floral ascendente, pubescente, geniculado muitas vezes encostando no utrículo, 2-4,5 x 1-1,5 cm na base, 1,3-1,9 cm larg. nos lábios. Utrículo oblongóide a ovóide, 2,5-3,5 x 1,2-1,8 cm. Ginostêmio séssil, campanulado, 0,9-1 x0,5-0,7 cm; lobos estigmáticos oblongos; anteras lineares. Cápsula cilíndrica, glabra, lisa, 8,3-8,5 x 1,7-2,2 cm; rostrada, rostro aprox. $0,5 \mathrm{~cm}$ compr. Sementes cordiformes, espessas, 0,55-0,6 x 0,6 cm, aprox. $0,1 \mathrm{~cm}$ de espessura; face adaxial escura, verrucosa, face abaxial clara, com nervura central.

Material selecionado: BRASIL. Paraná: Guaíra, Sete Quedas, 16.09.1981, fl., G. Hatschbach 43379 (MBM); Guaraqueçaba, Salto Morato, 15.11.1993, fr., G. Hatschbach \& J. M. Silva 59774 (MBM); Jaguaraiaíva, Parque Estadual Cerrado, Rio Santo Antônio, 29.10.1999, fl., L. v. Linsingen 141 (MBM).

Ahumada (1975) afirma que a espécie é limitada às manchas de cerrado existentes no $2^{\circ}$ planalto paranaense, porém, a espécie foi coletada também na Floresta Estacional Semidecidual, na região noroeste do Estado e na Floresta Ombrófila Densa, mais precisamente na região de Guaraqueçaba, mostrando uma distribuição não tão delimitada.

Esta espécie pode ser bem reconhecida pelas suas folhas e flores, sendo que Hoehne (1942) afirma uma transição entre as unilabiadas e caudadas do gênero, distinguindo-se de todas as afins. Não apresenta pseudoestípulas, característica que, com a presença da flor é facilmente reconhecida.

2. Aristolochia elegans Mast., Gard. Chron., n.s., 24(610): 301, pl. 64. 1885.

Fig. 2 e 3

Liana. Caule suberoso. Ramos sulcado-estriados, entrenós 3-17,5 cm compr. Pseudoestípulas orbiculares, base cordada, 1,3-2,7 x 1,2-2,8 cm. Folhas glabras; pecíolo 2,1-8 cm compr.; lâmina deltóide-cordiforme, 3,3-10,1 x 5-12,7 $\mathrm{cm}$, em geral mais largas que longas, base cordado-lobada, ápice arredondado a obtuso, raro agudo, 5-venada. Flor solitária, axilar; pedúnculo 5-13,5 cm compr.; perigônio unilabiado, glabro; lábio peltado, ovalado, 5,2-8,3 x 3-6,6 $\mathrm{cm}$, interiormente com máculas e estrias púrpuras, base le- vemente cordada, ápice emarginado. Tubo floral geniculado, fortemente curvado para cima, 0,5-2,8 x 0,4-1 cm na base, 1,2-2 cm larg. no lábio, externamente verde-amarelado. Utrículo oval-elipsóide, 2,2-6,8 x 1,1-2 cm, externamente verde-amarelado. Ginostêmio subséssil, levemente campanulado, 0,5-0,7 x 0,35 cm; lobos estigmáticos subtriangulares; anteras oblongas. Cápsula oblonga, glabra, lisa, 4-8,5 $\mathrm{x}$ 1,4-7 cm, rostrada, com disco apical, rostro $1 \mathrm{~cm}$ compr. Sementes obovadas, 0,5-0,7 x 0,4-0,5 cm, faces adaxial e abaxial verrucosas.

Material selecionado: BRASIL. Paraná: Curitiba, 15.12.1996, fl., A. C. Cervi \&M. T. Coelho6107 (MBM); Jardim Social, 20.11.2007, fl. e fr., D. S. Nascimento 269 (UPCB); Marechal Cândido Rondon, Bom Jardim, 10.12.1977, fl., G. Hatscbach 40566 (MBM); Santa Mariana, 21.08.1995, fl. e fr., M. V. Tomé 493 (FUEL); Santo Antônio de Caiuá, Rio Paranapanema, 23.06.1996, fl., G. Hatscbach 14491 (FUEL); Terra Roxa, 01.01.1997, fr., C. Kozera 303 (FUEL).

Possui grande distribuição nas Américas, sendo cultivada no Paraná. A espécie tem afinidade com A. gigantea, diferenciando-se da mesma pelo menor tamanho das flores e pelas folhas mais deltóides. A semelhança entre as duas espécies é confirmada por vários autores (Hoehne 1942; Barringer 1983; González 1990), apresentando em seu caule quando velho uma capa suberosa separada em bandas longitudinais, semelhante à de $A$. gigantea. As flores de $A$. elegans se assemelham às de $A$. odoratissima, diferenciando-se da mesma pelas folhas, frutos e sementes (González 1990).

3. Aristolochia fimbriata Cham. \& Schltdl., Linnaea 7: 210, pl. 100, f. 2. 1832.

Fig. 4

Erva ereta ou prostrada. Ramos sulcado-estriados, glabros, cilíndricos, entrenós 3,7-12,5 cm compr. Pseudoestípulas ausentes. Folhas glabras; pecíolo 3-8,6 cm compr.; lâmina reniforme, às vezes cordiforme, 4,5-6,3 x 5-7,5 cm, base cordado-lobada, ápice arredondado, 3-5-venada. Flor solitária, axilar; pedúnculo 1,5-3,8 cm compr.; perigônio unilabiado, glabro; lábio suborbicular, quase peltado, 0,9-2,1 x 1,4-2,4 cm, verrucoso, margem fimbriada, fímbrias sinuosas, 0,1-0,7 cm compr., curvadas na metade superior. Tubo floral ascendente, $0,6-1,3 \times 0,3-0,6 \mathrm{~cm}$ na base, 0,4-0,6 cm larg. no lábio. Utrículo globoso a ovóide, 1,2-2,4 x 0,9-1,6 cm. Ginostêmio estipitado, campanulado, 0,4-0,5 x 0,3$0,51 \mathrm{~cm}$; lobos estigmáticos triangulares; anteras oblongas. Cápsula oblonga, glabra, lisa, 1,4-2,8 x 0,5-1,5 cm, rostrada, rostro 0,1-0,2 cm compr. Sementes cordiformes, espessas, algo côncavas, $0,35-0,5 \times 0,38-0,4 \mathrm{~cm}$, face abaxial clara, verrucosa, face abaxial escura, verrucosa, com haste central proeminente.

Material examinado: BRASIL. Paraná: Cruz Machado, Santana, 08.01.1996, fl. e fr., C. Kozera et al. 36 (UPCB).

Material adicional examinado: BRASIL. Santa Catarina: São Joaquim, 21.01.1958, fr., J. R. Mattos 5861 (HBR). 
Essa espécie é umas das mais raras dentre as do gênero Aristolochia no Paraná, sendo a primeira ocorrência para o estado. Ocorre com mais frequência no Rio Grande do Sul e apresenta pouquíssimas coletas no estado de Santa Catarina. No estado do Paraná, foi coletada na região da Floresta Ombrófila Mista Alto-Montana. A. fimbriata pode ser encontrada em zonas de transição destas formações (Floresta Estacional / Floresta Ombrófila Mista, Estepe / Floresta Estacional). A. fimbriata apresenta talo hipógeo napiforme, suberoso estriado-sulcado, que atinge até $25 \mathrm{~cm}$ de comprimento. Seu caule é ascendente até encontrar um suporte e então torna-se apoiante (Ahumada 1967).

4. Aristolochia gigantea Mart. \& Zucc., Nov. Gen. Sp. Pl. 1: 75, pl. 48. 1824.

Fig. 5-7

Liana. Caule suberoso. Ramos sulcado-estriados, glabros, entrenós 4,8-9,5 cm compr. Pseudoestípulas cordiformeovaladas, $1,2-3 \times 1-2,8 \mathrm{~cm}$, base cordada, geralmente ausentes nos ramos mais novos. Folhas glabras; pecíolo levemente sulcado, 3,5-9,6 cm compr.; lâmina cordiforme a cordiformeovalada, 6,7-12 x 5,6-10,5 cm, base cordado-lobada, ápice obtuso, às vezes agudo ou acuminado, raramente arredondado, 5-7-venada. Flor solitária, axilar, pêndula; pedúnculo floral 16,6-29 cm compr.; perigônio unilabiado, glabro; lábio peltado, subovalado, $27-37$ x 20-27 cm, interior com manchas purpúreas, base cordada, ápice arredondado-emarginado. Tubo floral curto, ascendente, 2,7-4 x 0,6-1,5 cm na base e 1,7-2,1 cm larg. no lábio. Utrículo obovóide; base estreita, abrigando o ginostêmio; 5,8-9 x 3-6,5 cm. Ginostêmio subséssil, campanulado a estipitado, 1,5-1,7 x 0,7-0,9 cm; lobos estigmáticos oblongos; anteras lineares. Cápsula cilíndrica, glabra, 11-11,6 x 2-2,5 cm, rostrada, com disco apical, rostro 0,6-1 cm compr. Sementes ovaladas ou triangulares, achatadas, $0,9-1,1 \times 0,7-0,8 \mathrm{~cm}$, face adaxial, verrucosa, face abaxial escura com nervura central.

Material examinado: BRASIL. Paraná: Curitiba, Barreirinha, 03.03.2007, fl., D. S. Nascimento 262 (UPCB); Horto Botânico, 05.10.1983, fl., J. Cordeiro 30 (HUCP); Jundiaí do Sul, Fazenda Monte Verde, 23.03.2007, fr., D. S. Nascimento \& E. Barbosa 264 (HUCP); Paranaguá, 01.01.1996, fl., V. B. Souza 1 (HUCP); Tibagi, Estrada para o Salto Rosa, Barreiro, 18.12.1996, fl., J. M. Silva et al. 1869 (MBM).

A espécie é nativa da região centro-oeste do Brasil (Ahumada 1975), sendo encontrada cultivada no Estado do Paraná. Quando mais velha, apresenta o caule suberoso sulcado-estriado, assim como em A. elegans, assemelhandose a esta pelas folhas, da qual, sem flores, dificilmente pode ser separada.

A espécie às vezes é confundida e determinada como $A$. cordiflora Mutis ex Kunth., porém, apesar da semelhança da morfologia floral, as duas espécies apresentam algumas diferenças na morfologia das pseudoestípulas, base foliar, disposição das flores e área de distribuição, sendo A. cordiflora presente no Panamá, Colômbia e provavelmente, Costa Rica (Barringer 1983).

5. Aristolochia melastoma Silva Manso ex Duch., Prodr. 15(1): 460. 1864.

Fig. 8

Liana. Ramos sulcado-estriados, levemente sinuosos, pubescentes, entrenós 3,7-11,2 cm compr. Pseudoestípulas ausentes. Folhas com pecíolo de 0,6-2,5 cm compr., pubescente; lâmina lanceolada, às vezes oval-elíptica, 5,6$15,4 \times 1,4-2,9 \mathrm{~cm}$, face adaxial pubescente, face adaxial densamente pubescente; base cordado-lobada, lobos basais oblongo-reniformes, ápice obtuso, agudo, 3-venada. Flor axilar, inflorescência em racemo de 1,5-4 cm compr.; pedúnculo hirsuto $0,35-1,2 \mathrm{~cm}$ compr.; brácteas puberulentas, 0,25-0,4 x 0,12-0,2 cm; perigônio unilabiado, pubescente; lábio subpeltado, ovalado, côncavo, 1,5-3 x 1-2 cm, margem verrucosa, base levemente recurvada, ápice acuminado. Tubo floral geniculado, curvado para cima, 1,6-2,4 x 0,5-0,6 cm na base, , 0,7-1 cm larg. no lábio. Utrículo ovóide ou elipsóide, 0,7-1 x 0,5-0,7 cm. Ginostêmio estipitado, 0,21-0,3 x 0,1 cm; lobos estigmáticos triangulares; anteras oblongas. Cápsula oblonga a elíptica, glabra, lisa, 3,2-3,5 x 1,3-1,7 cm. Sementes ovaladas, espessas, $0,31-0,4 \times 0,28-0,3 \mathrm{~cm}, 0,1 \mathrm{~cm}$ de espessura; face adaxial escura, verrucosa, face abaxial clara.

Material examinado: BRASIL. Paraná: Arapoti, Faz. Barra Mansa, 21.01.1990, fl., J. T. Motta 1763 (MBM); Jaguariaíva, Rio Cilada, 10.01.1973, fl., G. Hatschbach 31115 (MBM); Jundiaí do Sul, Fazenda Monte Verde, 03.01.1999, fl., J. Carneiro 662 (MBM); Londrina, Faxinal São Sebastião, 11.03.1937, fl., G. Tessman 6103 (MBM); Terra Boa, Rio Ligeiro, 18.05.1969, fr., G. Hatschbach 21554 (MBM); Tibagi, Jaguatirica, Faz. Monte Alegre, 19.11.1953, fl., G. Hatschbach 3021 (MBM; HBR); Londrina, Fazenda Figueira-Paiquerê, 28.02.2003, fl., S. R. Slusarski et al. 260 (FUEL).

No Estado do Paraná, ocorre nas regiões de Floresta Estacional Semidecidual e de Floresta Ombrófila Mista, em áreas de vegetação secundária e antropizada. Apresenta inflorescência em racemo, caráter distinto da maioria das espécies paranaenses. Segundo Schinini \& López (1997) em algumas inflorescências podem ocorrer diferentes estados de desenvolvimento floral: botão, flor em antese e fruto em formação.

6. Aristolochia odoratissima L., Sp. Pl. (ed. 2) 2: 1362.1763 Fig. 9-10

Liana. Ramos sulcado-estriados, entrenós $5-12 \mathrm{~cm}$ compr. Pseudoestípulas elíptico-cordadas, 0,8-1,6 x 0,7$1,2 \mathrm{~cm}$. Folhas glabras, pecíolo 1,9-3,4 cm compr.; lâmina triangular-lanceolada a deltóide-lanceolada ou hastiforme, 7-13,3 x 4,5-7,9 cm; parte mediana às vezes ligeiramente mais larga, base cordado-lobada, lobos basais oblongos, 


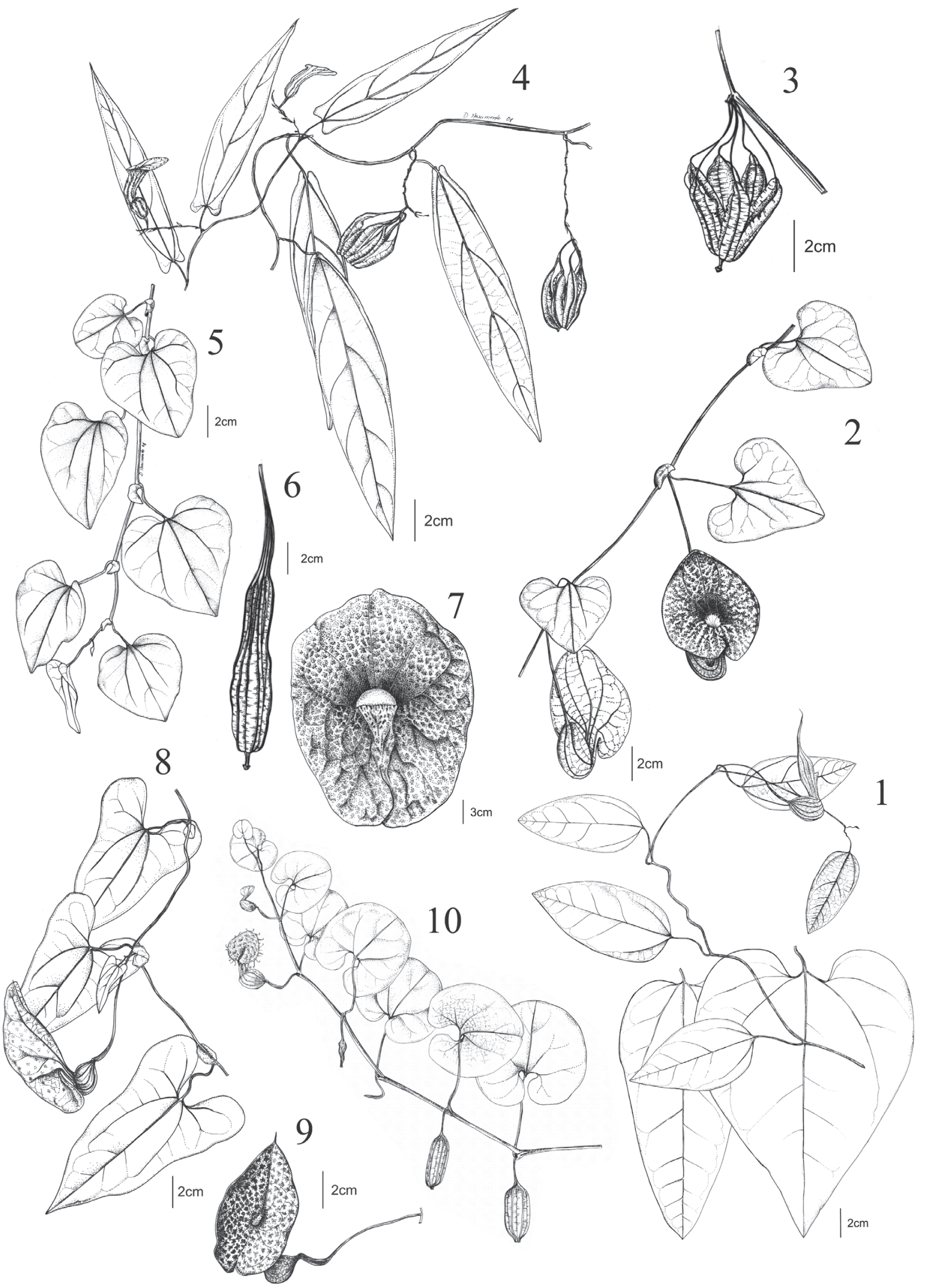

Figuras 1-10. Espécies de Aristolochiaceae que ocorrem no estado do Paraná. 1. Aristolochia chamissonis (Klotzsch) Duch. (L. v. Linsingen 141-B). 2-3. Ramo e fruto de Aristolochia elegans Mast. (D.S. Nascimento 267). 4. Aristolochia melastoma Silva Manso ex Duch. (S.R. Slusarski et al. 260; M.R. Pascoal et al. s.n'). 5-7. Ramo, fruto e flor de Aristolochia gigantea Mart \& Zucc. (D.S. Nascimento 264). 8-9. Ramo e flor de Aristolochia odoratissima L. (G. Hatschbach 5599). 10. Aristolochia fimbriata Cham. \& Schltdl. (J. Stehmann \& M. Sobral 844). 
ápice obtuso, raramente agudo, 5-7-venada. Flor solitária, axilar; pedúnculo 5-8 cm compr.; perigônio unilabiado, glabro externamente; lábio peltado, oblongo a ovalado, 3,9-9 x 3,2-5,6 cm, base cordada, ápice mucronado, Tubo floral ascendente, $0,7-1,5 \times 0,25-0,6 \mathrm{~cm}$ na base, $0,5-0,9 \mathrm{~cm}$ larg. no limbo. Utrículo ovóide, 1,7-2,2 x 1-1,4 cm. Ginostêmio estipitado, cilíndrico, 0,3-0,4 x 0,1-0,4 cm, lobos triangulares; anteras lineares. Cápsula n.v.

Material examinado: BRASIL. Paraná: Loanda, Porto São José, 08.04.1959, fl., G. Hatschbach 5599 (MBM; HBR).

Material adicional examinado: BRASIL. Mato Grosso do Sul: Antonio João, 3-6 km da cidade, 15.03.1985, fl., $G$. Hatschbach \& F. J. Zelma 49086 (MBM).

Amplamente distribuída em florestas úmidas de toda região neotropical (Barringer 1983). A espécie é rara no Paraná, tendo sua distribuição limitada ao noroeste do estado, em Floresta Estacional Semidecidual, ocorrendo geralmente ao longo do rio Paraná. Talvez extinta no estado, já que o local de sua única coleta (Loanda - Porto São José), é atualmente inundado. A. odoratissima assemelha-se a $A$. elegans pelo tamanho e coloração da flor, mas difere dela por apresentar o lábio mais estreito e lobos estigmáticos mais longos.

\section{Aristolochia paulistana Hoehne, Arch. Bot. São Paulo} 1: 13, pl. 4. 1925.

Fig. 11

Liana. Caule suberoso. Ramos sulcado-estriados, glabros; entrenós 3,3-17,6 cm compr. Pseudoestípulas suborbiculares, base cordada, $1-2,3 \times 1-2,3 \mathrm{~cm}$. Folhas com pecíolo de 2-6,5 cm compr., glabro; lâmina deltóide-triangular, 4,7-0,4 x 5-10,3 cm, face abaxial pubescente, base levemente cordada, muitas vezes truncada, ápice arredondado, às vezes obtuso, raramente emarginado, 3-5-venada. Flor axilar, solitária; pedúnculo 5,2-10,1 cm compr.; perigônio bilabiado, glabro; lábio superior ovalado-triangular, interiormente escabroso, base cordada, ápice prolongado em apêndice de 9-19,3 cm compr.; lábio inferior recurvado. Tubo floral ascendente, 1,5-4,4 x 1-2,4 $\mathrm{cm}$ na base, 1,2-1,8 cm larg. nos lábios. Utrículo ovóide, raramente globoso, base 6-partida, 2-3,9 x 1,2-2,6 cm. Ginostêmio estipitado, campanulado ou piriforme, $0,5-1,3 \times 0,4-0,6 \mathrm{~cm}$. Cápsula oblonga a cilíndrica, glabra, lisa, 4-6,1 x 2-2,7 cm, rostrada; rostro $0,6-0,7 \mathrm{~cm}$ compr. Sementes oval-deltóides, achatadas, 0,5-1 x 0,5-0,9 $\mathrm{cm}$, faces adaxial e adaxial verrucosas.

Material examinado: BRASIL. Paraná: Antonina, Reserva Natural do Cachoeira, Faisqueira, 07.10.2005, fl., F. B. Mattos \& P. B. Schwartsburd 861 (HUCP); Campina Grande do Sul, Serra do Espia, Rod. BR-2, 02.03.1964, fl., G. Hatschbach 11111 (MBM); Guaraqueçaba, 29.03.2007, fl., D. S. Nascimento \& E. Barbosa 265 (UPCB); Guaratuba, Serra de Araraquara, Morro do Cauvi, 30.12.1963, fl, G. Hatschbach 10869 (MBM); Morretes, Cadeado, 30.11.1966, fl, G. Hatschbach 15315
(MBM); Paranaguá, Morro Inglês, 26.11.2002, fl., O. S. Ribas et al. 4436 (MBM).

Ocorre na Floresta Ombrófila Densa Montana no estado do Paraná e em áreas de tensão ecológica, sendo mais comumente encontrada em pequenas clareiras e bordas da floresta. Sua flor se assemelha à de $A$. trilobata a qual apresenta 0 lábio superior com o apêndice um tanto maior. Sem as flores, a espécie pode ser confundida a $A$. elegans, $A$. gigantea $A$. triangularis, sendo suas folhas mais cartáceas.

8. Aristolochia triangularis Cham., Linnaea 7: 209, pl. 7. 1832.

Fig. 12-13

Liana. Caule suberoso. Ramos cilíndricos, sulcadoestriados, glabros; entrenós 3,1-15 cm compr. Pseudoestípulas suborbiculares a reniformes, 0,9-1,5 x 0,7-1,5 $\mathrm{cm}$. Folhas glabras; pecíolo 1,8-4,7 cm compr., glabro; lâmina deltóide-triangular, 4,5-10,6 x 2,8-8,2 cm; base levemente cordada, às vezes truncada, ápice obtuso a subagudo, 3-7-venada. Flor solitária, axilar, às vezes em inflorescência em racemo; pedúnculo 2-2,7 cm compr., bracteolado na base; perigônio peltilabiado, glabro ou levemente pubescente; lábio semiorbicular, 0,9-2 x 0,7-2 cm, interiormente com uma mancha amarela e estrias vináceas, margem pubescente, base emarginada, ápice arredondadomucronado. Tubo floral ascendente, fortemente ampliado para o lábio, 0,3-1,9 x 0,2-0,6 na base, 0,7-2 cm no lábio. Utrículo ovóide a globoso, 0,9-1,6 x 0,6-11 cm. Ginostêmio campanulado a ovóide, estipitado, $0,3 \times 0,2-0,3 \mathrm{~cm}$; lobos estigmáticos triangulares; anteras oblongas. Cápsula oblongo-elipsóide, glabra, com estrias proeminentes, 1,52,4 x 1-2,5 cm, rostrada; rostro $0,1-0,4 \mathrm{~cm}$. Sementes ovalcordiformes, achatadas, $0,5-0,6 \times 0,4-0,5 \mathrm{~cm}$, verrucosas; face abaxial com nervura central.

Material examinado: BRASIL. Paraná: Campina Grande do Sul, Sítio do Belizário, 17.08.1996, fl, O. S. Ribas 1487 (MBM); Curitiba, Abranches, 15.02.2008, fl., D. S. Nascimento 271 (UPCB); Foz do Iguaçu, Área prioritária Itaipu, 12.12.1982, fl., A. Buttura 779 (MBM); Piraquara, 25.12.1947, fl., G. Hatschbach 823 (PACA); Rio Branco do Sul, Caverna da Caximba, 13.09.1996, fl., A. C. Svolenski \& Tiepolo 269 (MBM).

Encontrada na orla de florestas, margem de rios, em capoeira alta, na vegetação de paredão rochoso, sendo muito comum em beira de estradas. Possui distribuição em várias formações vegetais, principalmente na Floresta Ombrófila Densa. Suas folhas se assemelham às de A. gigantea, sendo estas mais cordiformes. Segundo Hoehne (1942), a estrutura e o revestimento dos caules e ramos mais adultos não diferenciam essas duas espécies. Sua coloração varia muito de acordo com o local de desenvolvimento, na sombra são mais pálidas e ao sol mais escuras. Sua flor é algo semelhante à de $A$. wendeliana, diferindo no tamanho e formato do lábio. $\mathrm{Na}$ falta de apoio, torna-se rastejante. 


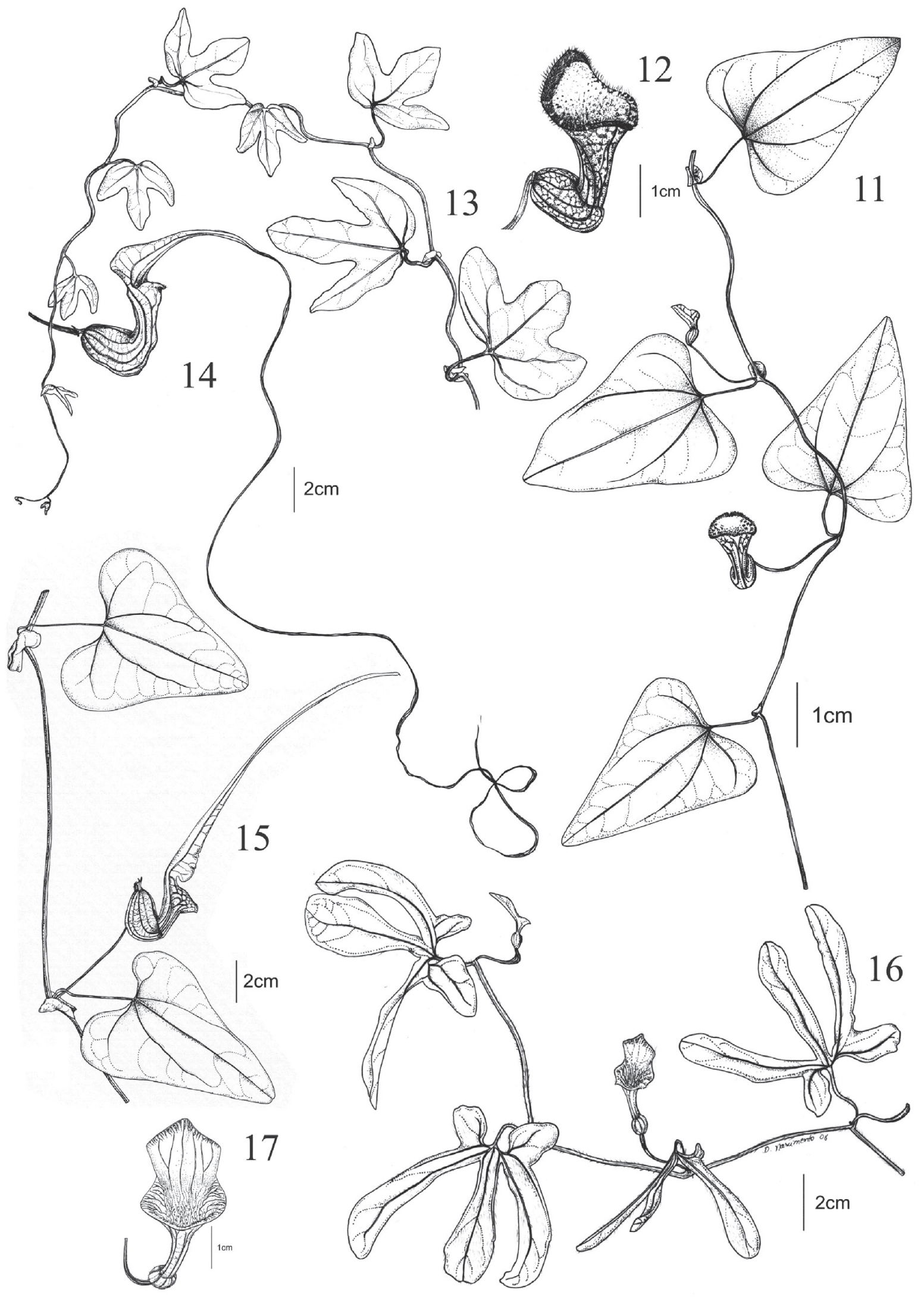

Figuras 11-17. Espécies de Aristolochiaceae que ocorrem no estado do Paraná. 11-12. Ramo e flor de Aristolochia triangularis Cham. (D.S. Nascimento 271). 13-14. Ramo e flor de Aristolochia trilobata L. (D.S. Nascimento 268; G. Hatschbach et al. 52292). 15. Aristolochia paulistana Hoehne (F. B. Mattos \& P. B. Schwartsburd 861). 16-17. Ramo e flor de Aristolochia wendeliana Hoehne (D.S. Nascimento 270). 


\section{Aristolochia trilobata L., Sp. Pl. 2: 960. 1753.} Fig. 14-15

Liana. Ramos cilíndricos, sulcado-estriados, glabros, entrenós 9-14,5 cm compr. Pseudoestípulas semi-orbiculares a cordiformes, 1,5-3,5 x 1,5-3 cm. Folhas com pecíolo de 2,2-9,8 cm de compr., glabro; lâmina profundamente trilobada, às vezes levemente trilobada, face abaxial híspida; lobo mediano auriculado, ápice agudo a acuminado, algumas vezes emarginado; lobos laterais elípticos a oblongos, ápice obtuso a arredondado, base levemente cordada, às vezes truncada, 5-venada. Flor axilar, solitária, raramente racemosa; pedúnculo 5-10 cm compr.; perigônio bilabiado, glabro; lábio superior ovalado-triangular, base cordada. ca. $3 \mathrm{~cm}$ larg., ápice prolongado num apêndice de 15-42 cm compr.; lábio inferior recurvado. Tubo floral ascendente, 2,7-4,5 x 1,4-2,5 cm nos lábios, interiormente escabroso. Utrículo ovóide, às vezes elipsóide, 2,6-5,3 x 2,1-3,1 cm, base 6-partida. Ginostêmio estipitado, campanulado, 1-1,1 x 0,6-1 cm. Cápsula cilíndrica, glabra, lisa, 6,1-7,2 x 2-2,6 $\mathrm{cm}$, rostrada; rostro aprox. $0,5 \mathrm{~cm}$ compr. Sementes deltóides, achatadas, $0,9 \times 0,7-0,8 \mathrm{~cm}$; face adaxial levemente verrucosa; face abaxial lisa.

Material examinado: BRASIL. Paraná: Guaratuba, Rio da Praia, 12.09.1963, fl., G. Hatschbach 10245 (MBM); Marechal Cândido Rondon, Córrego do Rio Branco, 18.09.1981, fl., G. Hatschbach 43997 (MBM); Paranaguá, Balneário Shangri-lá, 10.11.1972, fl., G. Hatschbach 30625 (MBM); Ilha do Mel, Praia da Fortaleza, 27.08.1988, fl., R. M. Britez et al. 1980 (MBM); Vila Alta, Parque Nacional Ilha Grande, s.d., fl., W. Amaral 707 (HFIE).

A espécie ocorre em Floresta Ombrófila Densa Montana, em orla de mangue e região de dunas. Sua presença é significativa em zonas de restinga, havendo um número relativamente considerável de coletas em tais locais. Segundo Ahumada (1975), a espécie é heliófita e seletiva xerófila, ocorrendo ao longo do litoral, e tendo seu limite sul de distribuição em Garopaba (SC).

Assemelha-se à A. paulistana quanto à flor e diferemse em relação às sementes. No primeiro caso, as duas são bilabiadas com lábio superior apendiculado, e no segundo as sementes diferem na superfície, a qual em $A$. paulistana apresenta-se verrucosa.

10. Aristolochia wendeliana Hoehne, Arq. Bot. Est. S. Paulo, n. s., v. 1, p. 45. 1939.

Fig. 16-17

Liana. Caule suberoso. Ramos sulcado-estriados, pubescentes em toda a extensão; entrenós 6,3-16,6 cm compr. Pseudoestípulas ausentes. Folhas com pecíolo de 1,2-4 cm compr., pubescente; lâmina 3-5-lobada; lobos muitas vezes irregulares ou assimétricos, 5-10,3 x 4,4-9,5 cm, face abaxial tomentosa, face adaxial pubescente, base lobada, ápice mediano agudo ou obtuso, raramente emarginado; lobos laterais arredondados; 5-7-venada. Flor axilar, solitária; pedúnculo floral pubescente, 2-2,2 cm compr.; perigônio unilabiado, peltilabiado; lábio oblongo, exterior pubérulo, interior escabroso, 1,2-1,7 x 0,8-1,2 cm; ápice levemente emarginado a agudo. Tubo ascendente, pubescente, $0,8-2 \times 0,2-0,4 \mathrm{~cm}$ na base, 0,4-1,2 cm larg. no lábio. Utrículo obovado a globoso, 0,6-0,8 x 0,4-0,6 cm. Ginostêmio estipitado, campanulado a ovalado, $0,35-0,45 \times 0,25-0,28 \mathrm{~cm}$, lobos triangulares; anteras oblongas. Cápsula oblonga, glabra, lisa, 3,3-3,8 x 07-0,9 cm, rostrada; rostro 0,5-0,7 cm compr. Sementes n. v.

Material examinado: BRASIL. Paraná: Cerro Azul, Boi Perdido, 04.10.1977, fl., G. Hatschbach 40214 (MBM); Curitiba, cultivada no Museu Botânico Municipal, 14.02.2008, fl., D. S. Nascimento 270 (UPCB); Irajá, 12.09.1988, fl. e fr., W. M. Kranz 376 (FUEL); Jundiaí do Sul, Fazenda Monte Verde, 23.03.2007, fl., D. S. Nascimento \& E. Barbosa 263 (MBM).

Trata-se de uma espécie rara, que se encontra na lista de ameaçadas de extinção do Estado do Paraná (Hatschbach \& Ziller 1995). Ocorre na Floresta Ombrófila Densa, possuindo sua distribuição atual restrita às regiões de Cerro Azul (PR) e proximidades, sendo cultivada nos demais locais do Paraná. Assim como sua ocorrência, muito pouco se refere na bibliografia sobre $A$. wendeliana.

Diferenciando-se de todas as espécies do gênero no Sul do Brasil, é a única que apresenta suas lâminas fortemente 5-lobadas, de tal modo que, sem as flores, pode ser confundida com representantes das Menispermáceas.

\section{Agradecimentos}

Ao Conselho Nacional de Desenvolvimento Cientifico e Tecnológico $(\mathrm{CNPq})$, pela bolsa concedida aos dois primeiros autores.

\section{Referências bibliográficas}

Ahumada, L.Z. 1967. Revision de las Aristolochiaceae Argentinas. Opera Lilloana 16: 1-145.

Ahumada, L.Z. 1975. Aristolochiaceae. Pp. 1-55. In: R. Reitz (ed). Flora Ilustrada Catarinense. Parte I, fasc. Aris. Itajaí, Herbário Barbosa Rodrigues.

Ahumada, L.Z. 1977. Novedades sistemáticas en el género Aristolochia (Aristolochiaceae) in Sudamérica, I. Darwiniana 21(1): 65-80.

Ahumada, L.Z. 1979. Novedades sistemáticas en el género Aristolochia (Aristolochiaceae) in Sudamérica, II. Hickenia 32(1): 171-184.

Batalha, M.A. \& Jorge, M.C.C. 2003. Aristolochiaceae. In: J.R. Pirani et al. (ed.) Flora de Grão-Mogol. Boletim de Botânica da Universidade de São Paulo 21(1): 1-24.

Barringer, K. A. 1983. Aristolochiaceae. In: Buerger (ed.), Flora Costaricensis. Fieldiana Botanic New Series 13: 79-87.

Barros, F. 1981. Flora Fanerogâmica da Reserva do Parque Estadual das Fontes do Ipiranga (São Paulo, Brasil). Hoehnea 9: 75-76.

Barros, F. \& Capellari Jr., L. 2004. Flora da Serra do Cipó, Minas Gerais: Aristolochiaceae. Boletim de Botânica da Universidade de São Paulo 22(1): 15-18.

Bazzolo, T.M. \& Pfeifer, H.W. 1977. Efimbriate, Herbaceous Aristolochias in Brazil and Northwest South América. Caldasia12(56): 19-33.

Capellari Jr., L. 1991. Aristolochiaceae. In: Wanderley, M.G.L.; Shepherd, G.J. \& Giulietti, A.M. (Orgs.) Flora Fanerogâmica de São Paulo 2: $39-49$.

Capellari Jr., L. 2001. Aristolochiaceae. In: J.A. Rizzo (ed.) Flora dos Estados de Goiás e Tocantins. Coleção Rizzo. Goiânia, Universidade Federal de Goiás, v.27, pp. 1-34 
Capellari Jr., L. 2002. Aristolochiaceae. Flora Fanerogâmica do estado de São Paulo 2: 39-49.

Cavalcanti, T.B. \& Ramos, A.E. 2001. Flora Do Distrito Federal. Brasília, Embrapa Recursos Genéticos E Biotecnologia.

Duchartre, P. 1864. Aristolochiaceae. In: A De Candolle (ed.). Prodromus Systematis Naturalis. 15(1): 421-498.

Engler, A. \& E. Gilg. 1912. Aristolochiales. Syllabus der Pflanzenfamilien. 7 ed. Gebrüder Borntraeger, 176-177.

Ferri, M.G., Menezes, N.L. \& Monteiro, W.R. 1981. Glossário ilustrado de Botânica. Nobel, São Paulo.

González G., F. A. 1990. Aristolochiaceae. Pp: 1-184. In: Rangel, J. O.; Cadena, A.; Correal, G. \& Bernal, R. (eds) Flora de Colômbia Bogotá, Instituto de Ciências Naturales.

González G., F. A. 1997. Hacia una filogenia de Aristolochia y sus congeneres neotropicales. Caldasia 19(1-2): 115-130.

González G., F.A. 2002. A new especies of Aristolochia (Aristolochiaceae) from Bahia, Brazil. Novon 10(4): 371-377.

Gregory, M.P. 1956. A phyletic rearrangement in the Aristolochiaceae. American Journal Botanic 43: 110-122.

Hatschbach, G.G. \& Ziller, S.R. 1995. Lista vermelha de plantas ameaçadas de extinção no Estado do Paraná. Curitiba, SEMA/GTZ.

Hoehne, F.C. 1927. Monografia ilustrada das Aristolochiaceas brasileiras. Memórias do Instituto Osvaldo Cruz 20: 67-175.

Hoehne, F. C. 1942. Aristolochiacea. Pp: 1-141. In; Hoehne, F.C. (ed.). Flora Brasilica 15(2): 1-141.

Holmgren, P.K., Holmgren, N.H. \& Barnett, L.C. 1990. Index Herbariorum. Part. I. The herbaria of the world. 8 ed. New York, The New York Botanical Garden.

Kelly, L.M. 1998. Phylogenetic relationships in Asarum (Aristolochiaceae) base don morphology and its sequences. American Journal of Botany 85(10): 1454-1467.
Lawrence, G.H.M. 1977. Taxonomia das plantas vasculares 2. Lisboa, Fundação Calouste Gulbenkian.

Maack, R. 1981. Geografia física do Paraná. 2 ed. Curitiba, Ed. Roessner. Masters, M.T. 1875. Aristolochiaceae. In: Martius, C.F.P.; Eichler, A.G.; Urban, I. (eds.). Flora Brasiliensis, Lipsiae 4 (2): 77-114.

Mendonça, R.D.; Felfili, J.M.; Walter, B.M.T.; Silva Jr., M.C. Da; Rezende, A.V.; Filgueiras, T. S. \& Nogueira, P.E. 1998. Flora Vascular Do Cerrado. In: Sano, S.M. \& Almeida, S.P. De (Eds.). Cerrado: Ambiente e Flora. Brasília, Embrapa-Planaltina, p. 287-556.

Pereira, E. 1959. Aristolochiaceae da cidade do Rio de Janeiro. Rodriguésia 21-22(33-34): 193-202.

Pfeifer, H.W. 1960. Flora of Panamá, Part. IV. Fasc. 3. Aristolochiaceae. Annals of the Missouri Botanical Garden 47(4): 309-323.

Pfeifer, H.W. 1966. Revision of the North and Central American hexandrous species of Aristolochia (Aristolochiaceae). Annals of the Missouri Botanical Garden 53(2): 115-196.

Radford, A.E; Dickison, W.C.; Massey, J.R. \& Bell, C.R. 1974. Vascular plant Systematics. New York, Harper \& Row Publishers.

Roderjan, C.V.; F. Galvão; Y.S. Kuniyoshi \& G.G. Hatschbach. 2002. As unidades fitoecológicas do Estado do Paraná. Ciência e Ambiente 24: 74-92.

Schinini, A. \& López, M.G. 1997. Novedades para la Flora Argentina encontradas en el Parque Iguazú (Missiones). Bonplandia 9(3-4): 231-236.

Schvartzman, J.B. 1975. Acción citostatica de una Aristolochiaceae paraguayana. Darwiniana 19: 2-4.

Stearn, W.T. 1983. Botanical Latin. Devon, David \& Charle

Wanke, S.; Jaramillo, M.A.; Borsch, T.; Samain, M.S.; Quandt, D. \& Neinhuis, C. 2007. Evolution of Piperales - matK gene and trnK intron sequence data reveal lineage specific resolution contrast. Molecular Phylogenetics and Evolution 42(2): 477-497. 